\title{
Prediction of osteoporotic fractures by postural instability and bone density
}

\author{
Tuan Nguyen, Philip Sambrook, Paul Kelly, Graeme Jones, Stephen Lord, Judith Freund, \\ John Eisman
}

\begin{abstract}
Objective-To investigate the utility of risk factors such as bone mineral density, lifestyle, and postural stability in the prediction of osteoporotic fractures.
\end{abstract}

Design-Longitudinal, epidemiological, and population based survey.

Setting-City of Dubbo, New South Wales.

Subjects-All residents of Dubbo aged $\geqslant 60$ on 1 January 1989.

Main outcome measure-Incidence of fracture for individual subjects.

Results-The overall incidence of atraumatic fractures in men and women was $1.9 \%$ and $3.1 \%$ per annum respectively. The predominant sites of fracture were hip $(18.9 \%)$, distal radius $(18 \cdot 5 \%)$, ribs and humerus $(11.9 \%$ in each case), and ankle and foot $(9 \cdot 1 \%$ and $6 \cdot 6 \%$ respectively). Major predictors of fractures in men and women were femoral neck bone mineral density, body sway, and quadriceps strength. Age, years since menopause, height weight, and lifestyle factors were also correlated with bone mineral density and body sway and hence were indirect risk factors for fracture. Discriminant function analysis correctly identified $96 \%$ and $93 \%$ (sensitivities $88 \%$ and $81 \%$ ) of men and women, respectively, who subsequently developed atraumatic fractures. Predictions based on this model indicated that a woman with a bone mineral density in the lowest quartile in the hip together with high body sway had a $8 \cdot 4 \%$ probability of fracture per annum. This represented an almost 14-fold increase in risk of fracture compared with a woman in the highest bone mineral density quartile with low postural sway. An individual with all three predictors in the "highest risk" quartile had a $13 \cdot 1 \%$ risk of fracture per annum.

Conclusions-Bone mineral density, body sway, and muscle strength are independent and powerful synergistic predictors of fracture incidence.

\section{Introduction}

The observation of the relation between bone loss and fracture was probably first made by Antley Cooper in 1824, when he suggested that the increase in frequency of fracture was due to thinning of bone in elderly people. ${ }^{1}$ Since then evidence has accumulated of an association between bone density and fracture. Population based studies show that hip fractures are uncommon among women with femoral neck bone mineral densities greater than the 70th centile of peak bone mass, but the frequency of fracture increases when bone mineral density falls below this level. ${ }^{23}$ Similarly, women in the lowest quintile of bone mineral content in the os calcis had a risk of non-spine fracture 10 times greater than women in the highest bone mineral content quintile. ${ }^{4}$

Bone mineral density is closely related to age, height, and weight. ${ }^{5-8}$ Lifestyle factors also influence bone mineral density. Muscle strength and aerobic fitness are positively associated with bone mineral density.9-11 Smoking has a negative effect on bone mineral density, ${ }^{12-15}$ although the mechanism of the effect of tobacco on bone is not completely understood. Interestingly, although excess alcohol intake is associated with an increased risk of fracture, ${ }^{16}$ moderate alcohol intake may have a "positive" effect on bone mineral density. ${ }^{17}$

Falls also seem to be important in the risk of fracture. Roughly one third of elderly people fall each year. ${ }^{18}$ Studies in institutional and community settings have identified an association between body sway and falls. ${ }^{19}$ The association is characterised by a significantly higher body sway and greater visual field dependence in the presence of moving visual stimuli (roll vection) and reduced tactile thresholds among fallers compared with non-fallers.

The utility of clinical risk factors in predicting osteoporotic fractures, however, is limited. In a study of 1014 women none of 12 factors that included age, metacarpal cortical area, Quetelet's index, age at menarche, parity, menopausal age, and gravidity were predictive of fracture. ${ }^{20}$ Similarly, although a risk factor questionnaire identified significant associations between age, height, time of menopause, and parity for vertebral fractures, their predictive value was poor. ${ }^{21}$ Other studies have generally examined the relation between risk factors and fractures in only one sex or at only one skeletal site. ${ }^{21-23}$

We report the findings of a longitudinal study of fracture incidence in a large population of both men and women in relation to potential predictors of fracture using a conventional statistical model of risk factors. This model is based on our hypothesis that age related fractures are a direct consequence of low bone density and falls due to impaired postural stability and locomotor weakness.

\section{Study design and population}

Dubbo is an isolated semiurban population of around 32000 situated $400 \mathrm{~km}$ north west of Sydney. The Dubbo osteoporosis epidemiology study invited all subjects over 60 identified from the electoral roll and residing in Dubbo city and the surrounding districts to attend. The aim was to relate osteoporotic fracture incidence, assessed prospectively, to baseline measures that included clinical risk factors for osteoporosis, bone mineral density, and measures of postural instability. The study began in 1989 , and at the time the target population comprised some 1690 men and 2161 women. ${ }^{24}$ The population was $98.6 \%$ white and $1.4 \%$ indigenous Aboriginal. Dubbo was selected because of its size and because the age and sex distribution of the population closely resembled the Australian population. Moreover, it was fairly isolated in terms of medical care, so that for certain health events (such as fractures) almost all were likely to be observed within the local public hospital or the single private radiological practice.

After giving informed consent subjects were interviewed by a nurse coordinator, who administered a structured questionnaire. Data collected included age, 
anthropometric variables (height, weight); reproductive history (age at menarche, gravidity, parity, years since menopause); lifestyle factors (dietary calcium, ${ }^{25}$ past and present tobacco use, alcohol consumption); history of use of medication; and history of falls (in the past 12 months). Fractures were identified prospectively from 1989 by reviewing all $x$ ray reports in Dubbo on subjects aged 60 or over at the only two radiology services available there (public hospital and private clinic) for the word "fracture." Vertebral fractures were included only if the clinical history suggested a recent symptomatic fracture and a previous $x$ ray picture showed no fracture.

Bone mineral density $\left(\mathrm{g} / \mathrm{cm}^{2}\right)$ was measured in the lumbar spine and femoral neck by dual energy $x$ ray absorptiometry with a Lunar DPX densitometer (Lunar Radiation Corporation, Madison, Wisconsin USA). The radiation dose with this method is $<0 \cdot 1$ $\mu \mathrm{Gy}$. The coefficient of variation with this method at our institution in normal subjects for bone mineral density is $1.5 \%$ for the lumbar spine and $1.3 \%$ for the femoral neck.

Postural instability testing included assessments of tactile sensitivity, quadriceps strength, roll vection, and body sway. Tactile sensitivity was measured at the lateral malleolus of the dominant leg with a SemmesWeinstein pressure aesthesiometer. ${ }^{26}$ Quadriceps strength (maximum isometric contraction) was measured in the sitting position in the subject's dominant (stronger) leg with a horizontal spring gauge calibrated to $50 \mathrm{~kg}$ force. Roll vection (visual field dependence to moving stimuli) was measured as the ability correctly to orient an adjustable straight edge to

TABLE I-Age and sex distribution of Dubbo target population and Dubbo osteoporosis epidemiology study sample

\begin{tabular}{|c|c|c|c|}
\hline Age (years) & $\begin{array}{c}\text { Dubbo } \\
\text { target } \\
\text { population }\end{array}$ & $\begin{array}{l}\text { Study } \\
\text { sample }\end{array}$ & $\begin{array}{c}\text { Atraumatic } \\
\text { fractures } \\
1989-92 \dagger\end{array}$ \\
\hline \multicolumn{4}{|c|}{ Males } \\
\hline $60-69$ & 949 & 422 & 32 \\
\hline $70-79$ & 588 & 246 & 39 \\
\hline$\geqslant 80$ & 153 & 41 & 18 \\
\hline Total & 1690 & 709 & 89 \\
\hline \multicolumn{4}{|c|}{ Females } \\
\hline $60-69$ & 1094 & 627 & 74 \\
\hline $70-79$ & 774 & 354 & 57 \\
\hline$\geqslant 80$ & 293 & 99 & 61 \\
\hline Total & 2161 & 1080 & 192 \\
\hline Total population aged $\geqslant 60$ & 3851 & 1789 & $281 \dagger$ \\
\hline
\end{tabular}

†Total fractures observed were 286 ; five subjects were not analysed owing to uncertain age.

TABLE II-Demographic and baseline characteristics of fracture versus non-fracture subjects. Figures are means (SD)

\begin{tabular}{|c|c|c|c|c|}
\hline & \multicolumn{2}{|c|}{ Males } & \multicolumn{2}{|c|}{ Females } \\
\hline & $\begin{array}{l}\text { Fracture } \\
\text { subjects }\end{array}$ & $\begin{array}{l}\text { Non-fracture } \\
\text { subjects }\end{array}$ & $\begin{array}{l}\text { Fracture } \\
\text { subjects }\end{array}$ & $\begin{array}{l}\text { Non-fracture } \\
\text { subjects }\end{array}$ \\
\hline Age (years) & $73 \cdot 7(8 \cdot 6)$ & $69 \cdot 4(6 \cdot 3)^{\star}$ & $73 \cdot 4(12 \cdot 3)$ & $69 \cdot 2(7 \cdot 4)^{\star}$ \\
\hline Height $(\mathrm{cm})$ & $170 \cdot 0(11 \cdot 3)$ & $173.4(7 \cdot 6)^{\star}$ & $156 \cdot 3(9 \cdot 8)$ & $160 \cdot 0(6 \cdot 5)^{\star \star}$ \\
\hline Weight (kg) & $74 \cdot 5(15 \cdot 7)$ & $78 \cdot 4(13 \cdot 8)$ & $58 \cdot 2(11 \cdot 7)$ & $65.9(13 \cdot 8)^{\star \star}$ \\
\hline $\begin{array}{l}\text { Lumbar spine bone mineral density } \\
\left(\mathrm{g} / \mathrm{cm}^{2}\right)\end{array}$ & $1.23(0 \cdot 23)$ & $1 \cdot 24(0 \cdot 19)$ & $0.92(0.17)$ & $1.03(0 \cdot 19)^{\star \star}$ \\
\hline $\begin{array}{l}\text { Femoral neck bone mineral density } \\
\left(\mathrm{g} / \mathrm{cm}^{2}\right) \\
\text { Body sway: }\end{array}$ & $0.87(0.16)$ & $0.91(0 \cdot 15)$ & $0.72(0.13)$ & $0.79(0.13)^{\star \star}$ \\
\hline On floors, eyes open $\dagger$ & $6.64(0.97)$ & $6.22(0.99)^{\star}$ & $6.49(1.18)$ & $6.27(10 \cdot 6)^{\star}$ \\
\hline On floors, eyes closed $\dagger$ & $6.50(0.92)$ & $6 \cdot 10(0.94)^{\star \star}$ & $6.44(1.09)$ & $6.21(0.98)^{\star}$ \\
\hline On foam, eyes opent & $7.34(0.96)$ & $6.85(0.92)^{\star \star}$ & $7 \cdot 21(1 \cdot 12)$ & $6.86(0.97)^{\star \star}$ \\
\hline On foam, eyes closed $\dagger$ & $6.83(0.97)$ & $6.43(0.92)^{\star}$ & $6.91(1.08)$ & $6.51(0.91)^{\star \star}$ \\
\hline Quadriceps strength $\ddagger$ & $3.25(0.60)$ & $3.46(0.37)^{\star \star}$ & $2.77(0.46)$ & $2.90(0.42)^{\star \star}$ \\
\hline Dietary calcium (kg/day) & $604(311)$ & $632(339)$ & $684(388)$ & $625(332)$ \\
\hline Tobacco intake & $5.52(0.69)$ & $5.75(0.67)$ & $5.46(0.58)$ & $5.33(0.66)$ \\
\hline Alcohol intake\| & $2.98(0.86)$ & $2.91(0.90)$ & $2.47(0.68)$ & $2.42(0.71)$ \\
\hline
\end{tabular}

$p$ Value of difference between fracture and non-fracture subjects: ${ }^{\star}<0 \cdot 05 ;{ }^{\star}<0.01$

tNatural logarithm of area $\left(\mathrm{mm}^{2}\right)$ traversed by pen on sway meter in 30 seconds. $¥$ Natural logarithm of $\mathrm{kg}$.

@Natural logarithm of pack year. |Natural logarithm of alcohol intake $(\mathrm{g})$. the vertical against a rotating striped background. ${ }^{27}$ Body sway was measured by using a simple sway meter that measured displacements of the body at the level of the waist in 30 second periods. Sway was measured under four test conditions: eyes open, firm surface (wooden floor); eyes closed, firm surface; eyes open, compliant surface (high density foam $1 \mathrm{~m}$ square, by $15 \mathrm{~cm}$ high); and eyes closed, compliant surface. Full descriptions of the appliances and procedures along with test and retest reliability scores (and confidence intervals) have been given elsewhere. ${ }^{28}$

\section{STATISTICAL METHODS}

The analyses began with a search for a set of variables with maximum discriminatory power to classify fracture versus non-fracture cases. Ten variables (including lifestyle factors, age, height, weight, bone mineral density, and postural instability parameters) were initially considered in formulating a discriminant model, the probability for entry to the final model being set at $0 \cdot 15$. We employed three algorithms of selection-stepwise and backward and forward elimination-and all suggested the same set of variables for the final logistic equation-namely, bone mineral density in the femoral neck, quadriceps strength, and body sway.

Having obtained a set of variables, we modelled the data according to the logistic function ${ }^{29}$ using the maximum likelihood approach. In this model we estimated the odds of probability of fracture over probability of non-fracture (which we treated as a fracture risk score) for individual subjects conditioned on his or her own characteristics. We then used the fracture risk score to classify fracture and non-fracture cases by selecting different cut off points. In order to assess whether the predictions derived from the logistic equation would replicate on another sample of subjects we randomly divided the data into two samples of about equal size and used the estimated coefficients to calculate the fracture risk score and the index of concordance ${ }^{30}$; this may be viewed as the area under the receiving operating characteristic curve. ${ }^{31}$ In a further analysis we applied the discriminant analysis ${ }^{32}$ to classify fracture and non-fracture cases with various defined probabilities; subsequently the predictive value of the model was evaluated by specificity and sensitivity probabilities. All data management and statistical computations were done with the SAS system..$^{33}$

\section{Results}

By May 1992, 1789 subjects (46\% of the target population) had undergone baseline measurements; 709 were men and 1080 women. Compared with the target population women had a slightly higher representation in the study sample than men $(50 \%$ and $42 \%$ respectively). The mean (SD) ages of men and women in the sample were $69.0(6 \cdot 3)$ and $69.2(6 \cdot 6)$ years respectively. The relative distribution of subjects with respect to age in the sample was not significantly different from that in the total target population (table I).

Between July 1989 and September 1992, 286 subjects aged 60 or over (195 women, 91 men) were identified from reports as having had at least one atraumatic fracture, making the overall incidence of atraumatic fractures in men and women in the total target population $1.9 \%$ and $3 \cdot 1 \%$ annually. Among both men and women the incidence of fractures increased with age. The incidence of atraumatic fractures in women was consistently higher than that in men across all age groups, though the magnitude of difference tended to decrease in the older age groups. The sites of fracture were similar in the two sexes. For 
TABLE III-Association between atraumatic fractures and bone density, sway, and quadriceps strength. Results expressed as maximum likelihood estimates of logistic regression coefficients (odds ratios) and 95\% asymptotic confidence intervals

\begin{tabular}{lccc}
\hline & & $\begin{array}{c}\text { Estimated odds ratio } \\
(95 \% \text { confidence } \\
\text { interval })\end{array}$ & $\begin{array}{c}\text { Standardised } \\
\text { estimate }\end{array}$ \\
\hline & SD & & \\
\hline $\begin{array}{c}\text { Males: } \\
\quad \text { Femoral neck bone mineral } \\
\text { density }\end{array}$ & 0.15 & $1.98(1.51$ to 2.61$)$ & 0.437 \\
$\begin{array}{l}\text { Quadriceps strength } \dagger \\
\text { Body sway on foam, eyes } \\
\text { closedt }\end{array}$ & 0.61 & $1.65(1.32$ to 2.07$)$ & 0.524 \\
$\begin{array}{c}\text { Females: } \\
\text { Femoral neck bone mineral } \\
\text { density }\end{array}$ & 0.95 & $2.23(1.68$ to 3.03$)$ & 0.310 \\
$\begin{array}{l}\text { Quadriceps strength } \dagger \\
\text { Body sway on foam, eyes } \\
\text { opent }\end{array}$ & 0.13 & $2.39(1.92$ to 2.97$)$ & 0.556 \\
\hline
\end{tabular}

†Based on natural logarithmic transformation.

TABLE IV-Incidence of fractures per 100 person years classified by quartiles of femoral neck bone mineral density, body sway, and quadriceps strength and according to composite risk score

\begin{tabular}{|c|c|c|c|c|c|c|c|}
\hline \multicolumn{4}{|c|}{ Males } & \multicolumn{4}{|c|}{ Females } \\
\hline $\begin{array}{l}\text { Quartile } \\
\text { (actual value) }\end{array}$ & $\begin{array}{c}\text { Total } \\
\text { subjects }\end{array}$ & Fractures & $\begin{array}{l}\% \text { Per } \\
\text { annum }\end{array}$ & $\begin{array}{l}\text { Quartile } \\
\text { (actual value) }\end{array}$ & $\begin{array}{c}\text { Total } \\
\text { subjects }\end{array}$ & Fractures & $\begin{array}{l}\% \text { Per } \\
\text { annum }\end{array}$ \\
\hline \multicolumn{8}{|c|}{ Femoral neck bone mineral density } \\
\hline $\begin{array}{l}1\left(\leqslant 0.82 \mathrm{~g} / \mathrm{cm}^{2}\right) \\
2\left(0.83-0.91 \mathrm{~g} / \mathrm{cm}^{2}\right) \\
3\left(0.92-1.00 \mathrm{~g}^{2} \mathrm{~cm}^{2}\right) \\
4\left(\geqslant 1.01 \mathrm{~g} / \mathrm{cm}^{2}\right)\end{array}$ & $\begin{array}{l}182 \\
178 \\
171 \\
169\end{array}$ & $\begin{array}{r}18 \\
5 \\
9 \\
6\end{array}$ & $\begin{array}{l}3 \cdot 30 \\
0 \cdot 94 \\
1 \cdot 75 \\
1 \cdot 18\end{array}$ & $\begin{array}{l}1\left(\leqslant 0.70 \mathrm{~g} / \mathrm{cm}^{2}\right) \\
2\left(0.71-0.78 \mathrm{~g} / \mathrm{cm}^{2}\right) \\
3\left(0.79-0.87 \mathrm{~g} / \mathrm{cm}^{2}\right) \\
4\left(\geqslant 0.88 \mathrm{~g} / \mathrm{cm}^{2}\right)\end{array}$ & $\begin{array}{l}282 \\
269 \\
265 \\
258\end{array}$ & $\begin{array}{l}54 \\
24 \\
13 \\
13\end{array}$ & $\begin{array}{l}6 \cdot 38 \\
2 \cdot 97 \\
1 \cdot 64 \\
1 \cdot 68\end{array}$ \\
\hline \multicolumn{8}{|c|}{ Body sway on foam, eyes closed } \\
\hline $\begin{array}{l}1\left(\leqslant 510 \mathrm{~mm}^{2}\right) \\
2\left(511-874 \mathrm{~mm}^{2}\right) \\
3\left(875-1667 \mathrm{~mm}^{2}\right) \\
4\left(\geqslant 1668 \mathrm{~mm}^{2}\right)\end{array}$ & $\begin{array}{l}168 \\
172 \\
183 \\
174\end{array}$ & $\begin{array}{r}5 \\
8 \\
11 \\
14\end{array}$ & $\begin{array}{l}0.99 \\
1.55 \\
2.00 \\
2.68\end{array}$ & $\begin{array}{l}1\left(\leqslant 378 \mathrm{~mm}^{2}\right) \\
2\left(379-621 \mathrm{~mm}^{2}\right) \\
3\left(622-1125 \mathrm{~mm}^{2}\right) \\
4\left(\geqslant 1126 \mathrm{~mm}^{2}\right)\end{array}$ & $\begin{array}{l}270 \\
263 \\
271 \\
267\end{array}$ & $\begin{array}{l}17 \\
11 \\
17 \\
58\end{array}$ & $\begin{array}{l}2 \cdot 10 \\
1 \cdot 39 \\
2 \cdot 09 \\
7 \cdot 24\end{array}$ \\
\hline \multicolumn{8}{|c|}{ Quadriceps strength } \\
\hline $\begin{array}{l}1(\leqslant 26 \mathrm{~kg}) \\
2(27-33 \mathrm{~kg}) \\
3(34-43 \mathrm{~kg}) \\
4(\geqslant 44 \mathrm{~kg})\end{array}$ & $\begin{array}{l}178 \\
189 \\
170 \\
164\end{array}$ & $\begin{array}{r}22 \\
3 \\
7 \\
6\end{array}$ & $\begin{array}{l}4 \cdot 12 \\
0 \cdot 53 \\
1 \cdot 37 \\
1 \cdot 22\end{array}$ & $\begin{array}{l}1(\leqslant 14 \mathrm{~kg}) \\
2(15-19 \mathrm{~kg}) \\
3(20-24 \mathrm{~kg}) \\
4(\geqslant 25 \mathrm{~kg})\end{array}$ & $\begin{array}{l}252 \\
270 \\
269 \\
258\end{array}$ & $\begin{array}{l}51 \\
21 \\
14 \\
18\end{array}$ & $\begin{array}{l}6 \cdot 75 \\
2 \cdot 59 \\
1 \cdot 73 \\
2 \cdot 33\end{array}$ \\
\hline
\end{tabular}

\begin{tabular}{|c|c|c|c|c|c|c|c|}
\hline \multicolumn{8}{|c|}{ Composite scores } \\
\hline Score $0 \dagger$ & 6 & 0 & 0 & 0 & 13 & 0 & 0 \\
\hline$\Rightarrow 1$ & 17 & 2 & 3.92 & 1 & 49 & 5 & $3 \cdot 40$ \\
\hline$\Rightarrow 2$ & 54 & 3 & 1.85 & 2 & 100 & 7 & 2.33 \\
\hline$\# 3$ & 92 & 3 & 1.09 & 3 & 154 & 3 & 0.65 \\
\hline$\Rightarrow 4$ & 117 & 4 & $1 \cdot 14$ & 4 & 201 & 13 & $2 \cdot 16$ \\
\hline$\Rightarrow 5$ & 150 & 4 & 0.89 & 5 & 167 & 12 & $2 \cdot 40$ \\
\hline$\Rightarrow 6$ & 124 & 4 & 1.08 & 6 & 182 & 5 & 0.92 \\
\hline$\Rightarrow 7$ & 54 & 6 & $3 \cdot 70$ & 7 & 67 & 17 & $8 \cdot 46$ \\
\hline & 36 & 3 & $2 \cdot 78$ & 8 & 63 & 16 & 8.47 \\
\hline$\geqslant 9$ & 35 & 9 & 8.57 & 9 & 54 & 26 & 16.05 \\
\hline
\end{tabular}

†Composite risk score derived by dividing the three predictor variables into quartiles, scoring each from zero to 3 , and summing to get total score.

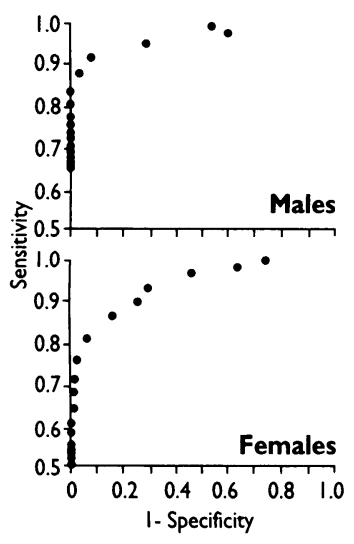

Receiving operating characteristic curves for classification of fracture versus non-fracture cases in males and females

significant difference in dietary calcium intake was found between the two groups. Women who suffered fractures had some $5-10 \%$ lower bone mineral density in the spine and the hip, whereas men who suffered fractures had significantly lower bone mineral density in the hip but not in the spine. In both sexes fracture strength, and body sway (on foam, eyes closed) were significant predictors of fractures, whereas age, years since menopause, body weight, and height did not reach the significance level of $15 \%$ to be included in the final logistic model. Maximum likelihood estimates and associated statistics are given in table III. As the parameters were measured in different units, standardised estimates were also computed to provide a means of assessing the relative importance of each factor to the discrimination between fracture versus non-fracture cases.

For women bone mineral density in the femoral neck had the largest power to discriminate between fracture and non-fracture cases, followed by sway and quadriceps strength. A decrease of one standard deviation $\left(0.13 \mathrm{~g} / \mathrm{cm}^{2}\right)$ in femoral bone mineral density and a one standard deviation increase in sway $\left(134 \mathrm{~mm}^{2}\right)$ were independently associated with a $2 \cdot 4$-fold $(95 \%$ confidence interval 1.93 to 2.97 ) and a 1.7 -fold increase in risk of fracture, respectively. In contrast, in men quadriceps strength was the most important factor in discriminating fracture and non-fracture cases, followed by bone mineral density and sway. It was estimated that a decrease of one standard deviation in quadriceps strength $(11 \mathrm{~kg})$ and in femoral neck bone mineral density $\left(0 \cdot 16 \mathrm{~g} / \mathrm{cm}^{2}\right)$ was associated with a $2 \cdot 2$ fold and a $2 \cdot 0$-fold increase, respectively, in risk of atraumatic fracture.

There was strong evidence that fractures (in both males and females) occurred most frequently in subjects in the lowest femoral neck bone mineral density quartile (for males $\leqslant 0.82 \mathrm{~g} / \mathrm{cm}^{2}$, for females $\leqslant 0.70$ $\mathrm{g} / \mathrm{cm}^{2}$ ), lowest quadriceps strength quartile (for males $\leqslant 26 \mathrm{~kg}$, for females $\leqslant 14 \mathrm{~kg}$ ), and highest sway quartile (for males $\geqslant 1668 \mathrm{~mm}^{2}$, for females $\geqslant 1126 \mathrm{~mm}^{2}$ ) (table IV). In subjects with all three predictor variables in the highest risk quartile for that variable (that is, lowest femoral neck bone density, lowest quadriceps strength, highest body sway) the composite risk of fracture was $13 \cdot 1 \%$ per annum (table IV).

Using expected values of the logistic equation based on the three variables, we derived fracture risk scores for each subject and classified fracture versus nonfracture subjects according to various cut off values. Specificity and sensitivity of prediction were then obtained. Generally, the discriminant model based on fracture risk score fitted the observed data well. Regardless of whether the data were fitted with low, intermediate, or high sensitivity the classification was highly specific $(70 \%$ to $100 \%$ for both men and women). For example, in women with fractures the three factors together (bone mineral density, quadriceps strength, body sway) could identify correctly about $98.6 \%$ of fracture cases with a sensitivity of $70 \%$. When data were fitted by a parsimonious model (incorporating sex effect in addition to the three risk factors) the index of concordance was $0 \cdot 83$. When data were randomly split into two subsamples the index of concordance was 0.84 and 0.81 respectively. These indices suggested that the logistic equation could discriminate between fracture and non-fracture cases with high accuracy. The receiving operating characteristic curves for both sexes are shown in the figure. subjects had a substantially higher body sway (more than $40 \%$ greater sway area on foam with eyes closed) and significantly lower quadriceps strength (more than $10 \%$ lower) compared with non-fracture subjects (table II).

Stepwise logistic regression analysis disclosed that femoral neck bone mineral density, quadriceps

\section{Discussion}

Various risk factors for osteoporotic fracture have been identified and can broadly be classified into two groups: risks factors that are related to bone mineral density and risk factors that are related to falls. Clinical risk factors for low bone mineral density have been well characterised in many studies, but models utilising such factors have had poor accuracy of prediction of fractures. Similarly, although clinical risk factors for 
falls have been identified, quantitative measures of postural stability have generally not been utilised in fracture prediction. In this study, using a conventional model for fracture prediction and the hypothesis that osteoporotic fractures are a direct consequence of low bone mineral density and poor postural stability (and hence falls), we have identified people who subsequently suffer fracture with high sensitivity and specificity.

Our findings with regard to the relation between fracture incidence and bone mineral density, anthropometric variables, and lifestyle factors are consistent with case-control studies that have shown that low bone mass, lighter body weight, early menopause, and smoking are associated with increased risk of fracture. The strength of the relation between bone mineral density and fracture risk (as represented by the odds ratio) observed in our population agrees closely with that of a recent study. ${ }^{35}$ However, we have also shown that subjects with fracture have significantly higher body sway and lower muscle strength than subjects without fracture and, more important, that age alone has no influence on the probability of fracture. The findings in subjects with all three predictors in the highest risk quartile suggest synergism between the predictor variables and may indicate that treatment to improve even one predictor variable (for example, bone density) could reduce the fracture risk substantially.

Body sway was a significant predictor of fractures in both sexes. Other studies have shown an association between body sway and falls. ${ }^{36-38}$ In males body sway on foam with eyes closed was a predictor, whereas in females body sway on foam with eyes open was significant. As all four measures of body sway-eyes open or closed, on and off foam-are correlated, this statistical difference is unlikely to have any clinical importance. Postural stability measurements were done at baseline, so the poorer performance in fracture patients could not have been affected by recent fracture. Moreover, measurements were done under close supervision in an unhurried fashion by experienced staff, so it is unlikely that subjects most at risk of falls performed badly because of perceived anxiety about the risk of falling during the procedure.

The finding that age was not an independent predictor of atraumatic fractures is of considerable interest. Hui et al identified age and bone mass as significant independent predictors. ${ }^{39}$ They, however, considered age as a surrogate for other age related factors. This agrees with our previous studies showing that physical fitness, muscle strength, and weight but not age were independent predictors of femoral neck

\section{Clinical implications}

- Risk factors for osteoporotic fracture include bone density, lifestyle factors, and impaired postural stability leading to falls

- Interactions between risk factors were investigated in a large population based community study

- Major predictors of incidence of fractures in both sexes included femoral neck bone density, lower limb muscle strength, and body sway

- Discriminant analysis using these predictors correctly classified osteoporotic fracture patients with high specificity and sensitivity

- These predictors were synergistic, so that a person with all three predictors in the highest risk quartile for that variable had a fracture risk of $13 \cdot 1 \%$ a year bone density. ${ }^{911}$ Our data suggest that postural stability may be one such major factor, as postural instability tends to worsen with age. Our finding of the effects of quadriceps strength in fracture incidence suggests that leg muscle strength may be important in the risk of falls and has therapeutic implications.

In conclusion our results support the hypothesis that bone mineral density, muscle strength, and body sway are independent predictors of the risk of age related fracture. This concept, which formed the basis for our study, has recently also been proposed by others. ${ }^{40}$ As fracture is a probabilistic event, the finding that fracture incidence was high among groups with the lowest bone mineral density and poor postural stability and low among subjects with high bone mineral density and good postural stability does not mean that those subjects will or will not necessarily sustain fractures. However, the study shows that high body sway and quadriceps weakness, which predispose to falls, are predictors of the probability of fracture independently of bone mineral density. These parameters should be valuable for assessing risk of fracture in other population groups.

We acknowledge the help of $\operatorname{Dr} R$ Slack-Smith in radiological analyses and Carol Gilbert, Louise Jones, and Susan Boyd in the measurement of postural stability and bone densitometry. This work was supported by the Australian Institute of Health and National Health and Medical Research Council of Australia. We also acknowledge the support of the Australian and New South Wales Dairy Corporations, the Dairy Promotion Council of New South Wales and New South Wales Milk Marketing, the Arthritis Foundation of Australia, Organon Australia, Curvilinear, Lunar Corporation, Ciba Geigy, Picksoft, and Epson Australia. Finally, we acknowledge the invaluable help of the staff of Dubbo Hospital, particularly Mr B Luton, Mr C Mitchell, Mr M Russell, and Mr B Ayrton.

1 Cooper A. Treatise on dislocation and fractures of the joints. 4 th ed. London: Longman, 1824 .

2 Melton LJ, Wahner HW, Richelson LS, O'Fallon MW, Riggs BL Osteoporosis and risk of hip fracture. Am 7 Epidemiol 1986;124:254-61.

3 Libanati CR, Schulz EE, Shook JE, Bock M, Baylink DJ. Hip mineral density in females with a recent hip fracture. $\mathcal{F}$ Clin Endocrinol Metab 1992;74:351-6.

4 Wasnich RD, Ross PD, Heilbrun LK, Vogel JM. Prediction of postmenopausal fracture risk with use of bone mineral measurements. Am $\mathcal{f}$ Obste Gynecol 1985;153:745-51.

5 De Schepper J, Derde MP, Van den Broeck M, Piepsz A, Jonckheer MH. Normative data for lumbar spine bone mineral content in children: influence of age, height, weight, and pubertal stage. $f$ Nucl Med 1990;32:216-20.

6 Gallagher JC, Goldgar D, Moy A. Total bone calcium in normal women effects of age and menopause status. 7 Bone Miner Res 1987;2:491-6.

7 Mazess RB, Barden HS, Drinka PL, Bauwens SF, Orwoll ES, Bell NH. Influence of age and body weight on spine and femur bone mineral density in US white men. $\mathcal{I}$ Bone Miner Res 1990;6:645-52.

8 Lindsay R, Cosman F, Herrington BS, Himmelstein S. Bone mass and body composition in normal women. $¥$ Bone Miner Res 1992;7:55-63.

9 Pocock NA, Eisman JA, Yeates MG, Sambrook PN, Eberl S. Physical fitness is a major determinant of femoral neck and lumbar spine bone mineral is a major determinant of femoral

10 Snow-Harter C, Bouxsein M, Lewis B, Charette S, Weinstein P, Marcus R Muscle strength as a predictor of bone mineral density in young women. f Bone Miner Res 1990;5:589-95.

11 Pocock N, Eisman J, Gwinn T, Sambrook P, Kelly P, Freund J, et al. Muscle strength, physical fitness and weight but not age predict femoral bone mass. f Bone Miner Res 1989;44:441-8.

12 Slemenda CW, Hui SL, Longcope C, Johnston CC. Cigarette smoking obesity and bone mass. $\mathcal{f}$ Bone Miner Res 1989;5:737-41.

13 Krall EA, Dawson-Hughes B. Smoking and bone loss among postmenopausa women. f Bone Miner Res 1991;4:331-7.

14 Mazess RB, Barden HS. Bone density in postmenopausal women: effects of age, dietary intake, physical activity, smoking and birth control pills. Am f Clin Nutr 1991:53:132-42.

15 Pocock N, Eisman J, Kelly J, Sambrook P, Yeates M. Effects of tobacco use on axial and appendicular bone mineral density. Bone 1989;10:329-31.

16 Hermandez-Avila M, Colditz GA, Stampfer MJ, Rosner B, Speizer FE Willett WC. Caffeine, moderate alcohol intake, and risk of fractures of the hip and forearm in middle-aged women. Am 7 Clin Nutr 1991;54:157-63.

17 Angus R, Sambrook PN, Pocock N, Eisman JA. Dietary intake and bone mineral density. Bone Miner 1989;4:265-77.

18 Blake AJ, Morgan K, Bendall MJ, Dallosso H, Ebrahim SBJ, Arie THD, et al Falls by elderly people at home: prevalence and associated factors. Age Ageing 1988;17:365-72.

19 Lord SR, Clark RD, Webster IW. Physiological factors associated with falls in an elderly population. $7 \mathrm{Am}$ Geriatr Soc 1991;39:1 194-200.

20 Van Hemert AM, Vandenbroucke JP, Birkenhager JC, Valkenburg HA Prediction of osteoporotic fractures in the general population by a fracture risk score. Am f Epidemiol 1990;132:123-35.

21 Cooper C, Shah S, Hand DJ, Adams J, Compston J, Davies M, et al. Screening for vertebral osteoporosis using individual risk factors. Osteoporosis International 1991;2:48-53. 
22 Melton LJ. Epidemiology of fractures. In: Riggs BL, Melton LJ, eds. Osteoporosis: etiology, diagnosis and management. New York: Raven Press, 1988:133-54.

23 Grisso JA, Chiu GY, Maislin G, Steinmann WC, Portable J. Risk factors for hip fractures in men: a preliminary study. $\mathcal{J}$ Bone Miner Res 1991;8:865-8.

24 Simons LA, McCallum J, Simons J, Powell I, Ruys J, Heller R, et al. The Dubbo study: an Australian prospective community study of the health of the elderly. Aust N Z F Med 1990;20:783-9.

25 Angus RM, Sambrook PN, Pocock NA, Eisman JA. A simple method for assessing calcium intake in Caucasian women. 7 Am Diet Assoc 1989;89: 209-14.

26 Semmes J, Weinstein S, Ghent L. Somatosensory changes after penetrating brain wounds in man. Cambridge, Massachusetts: Harvard University Press, 1960

7 Dichgans J, Held R, Young LR, Brandt T. Moving visual scenes influence the apparent direction of gravity. Science 1972;178:1217-9.

28 Lord SR, Clarke RD, Webster IW. Postural stability and associated physiological factors in a population of aged persons. I Gerontol 1991;46:M57-66. Cox DR, Snell EJ. The analysis of binary data. 2nd ed. London: Chapman \& Hall, 1989.

Hall, 1989 .
Harrell FE, Califf RM, Pryor DB, Rosati RA. Evaluating the yield of medical Harrell FE, Califf RM, Pryor DB,
tests. $f A M A$ 1982;247:2543-6.

31 Hanley JA, McNeil BJ. The meaning and use of the area under a receiving operating characteristic (ROC) curve. Radiology 1982;50:23-36.
32 Hand DJ. Discrimination and classification. New York: Wiley, 1982.

33 SAS Institute. SAS/STAT: user's guides. Cary, North Carolina: SAS Institute, 1990

34 Cooper C, Aitkinson EJ, O'Fallon WM, Melton LJ. Incidence of clinically diagnosed vertebral fractures: a population based study in Rochester, Minnesota, 1985-1989. F Bone Miner Res 1992;7:221-7.

35 Cummings SR, Black DM, Nevitt MC, Browner W, Cauley J, Ensrud K, et al. Bone density at various sites for prediction of hip fractures. Lancet 1993;341:72-5.

36 Brocklehurst JC, Robertson D, James-Groom P. Clinical correlates of sway in old age-sensory modalities. Age Ageing 1982;11:1-10.

37 Fernies GR, Gryfe CI, Holliday PJ, Lewellyn A. The relationship of postural sway in standing to the incidence of falls in geriatric subjects. Age Ageing 1982;11:11-6.

38 Lord SR, McLean D, Stathers G. Physiological factors associated with injurious falls in older people living in the community. Gerontolog 1992;38:338-46.

39 Hui SL, Slemenda CW, Johnton CC. Age and bone mass as predictors of fracture in prospective studies. $\mathcal{F}$ Clin Invest 1987;81:1804-9.

40 Cummings SR, Nevitt MC. A hypothesis: the causes of hip fractures $f$ Gerontol 1989;44:M107-11.

(Accepted 23 August 1993)

\title{
Influence of social deprivation on illness in diabetic patients
}

\author{
William F Kelly, Rashad Mahmood, \\ Miranda J Kelly, Steve Turner, Keith Elliott
}

Diabetes Care Centre, Middlesbrough General Hospital, Middlesbrough TS5 5 AZ

William F Kelly, consultant physician

Miranda J Kelly, diabetes

liaison sister

School of Computing and Mathematics, University of Teesside,

Middlesbrough TS1 3BA

Rashad Mahmood, student

Cleveland County Council

Research and Intelligence

Unit, Middlesbrough

TS1 2YW

Steve Turner, chief

statistician

Keith Elliott, research officer

Correspondence to:

Dr Kelly.

BMF 1993;307:1115-6
Inequalities in health are associated with social deprivation..$^{1-3}$ Our hospital serves a district of 286000 people with considerable differences in environmental and social circumstances. We therefore investigated whether illness in diabetic patients is linked to deprivation by analysing data on diabetic patients from contrasting socioeconomic backgrounds.

\section{Patients, methods, and results}

A standardised form for the diabetic register has been completed for all patients visiting this centre since 1984, and the results have been computerised since 1987. For this study we analysed demographic details and details of diabetic complications and treatment. The electoral wards where patients lived were determined from postal codes. The prosperity of wards was ranked using data on unemployment, no car ownership, overcrowding, the proportion of rented accommodation, and the proportion of households of socioeconomic classes 4 and $5 .^{2}$ Parametric and non-parametric statistics were used to compare patients from the most and least deprived wards; significance was taken as $\mathrm{p}<0.05$.

Of 1528 patients seen in 1991, 241 lived in the eight most deprived wards, 247 in the 10 least deprived wards, and 1040 in the remaining intermediate wards. Overall, 886 were men, 371 smoked, and only 81 were from ethnic minority groups; 161 were treated by diet alone, 586 with oral drugs, and 748 with insulin, with 33 not recorded.

The table shows that patients from the deprived inner city were significantly older with a shorter duration of diabetes than those from the properous wards. Insulin was used significantly less frequently in the inner city, where smoking was more common. Ischaemic heart disease and peripheral vascular disease were significantly more prevalent in the inner city. When smokers were analysed separately, ischaemic heart disease was no longer significantly associated with living in the inner city $(p=0.57$, odds ratio 1.3$)$; however, for non-smokers the association between ischaemic heart disease and living in the inner city remained significant $(p=0.0003$, odds ratio 2.81 (95\% confidence interval 1.51 to $5 \cdot 25)$ ). Proportionally more people from our district lived alone in the inner city than lived alone in the prosperous wards $(31 \% v 25 \%$ respectively).

\section{Comment}

Diabetic patients from the socially and economically deprived inner city were less likely to use insulin, and more likely to smoke and to have cardiovascular disease than were patients from the prosperous wards. Smoking ranged from $32 \%$ in the deprived inner city, to $25 \%$ in the intermediate area, to $19 \%$ in the prosperous wards. This increased prevalence of smoking among inner city residents has been noted previously ${ }^{4}$ and partly explains their high prevalence of ischaemic heart disease. Smoking is recorded at each visit to our clinic and advice is repeated to reduce and eventually stop smoking. The overall prevalence of smoking in our clinic has fallen from $26 \%$ in 1987 to $22 \%$ in 1992 .

Inner city residents are more likely to be older and living alone. They may therefore be reluctant to use insulin.

Previous reports have commented on the associations between poor housing, unemployment and poverty, and general health problems, including an increased risk of respiratory and cardiac disease and a decreased

Data on diabetic patients according to prosperity of electoral ward where they lived

\begin{tabular}{|c|c|c|c|c|c|}
\hline & \multicolumn{3}{|c|}{ Prosperity of ward } & \multirow[b]{2}{*}{$\begin{array}{c}\text { Odds ratio } \\
(95 \% \text { confidence interval })^{\star}\end{array}$} & \multirow[b]{2}{*}{ p Value } \\
\hline & $\begin{array}{l}\text { Deprived } \\
(n=241)\end{array}$ & $\begin{array}{l}\text { Intermediate } \\
(\mathrm{n}=1040)\end{array}$ & $\begin{array}{l}\text { Prosperous } \\
(\mathrm{n}=247)\end{array}$ & & \\
\hline Median age (range) (years) & $58(14-83)$ & $57(9-89)$ & $54(9-84)$ & & $0.018 t$ \\
\hline Median duration of diabetes (range) (years) & $6(1-51)$ & $8(1-59)$ & $9(1-43)$ & & $0.005 t$ \\
\hline \multicolumn{6}{|l|}{ Proportion $(\%)$ of patients: } \\
\hline Taking insulin & $101 / 234(43)$ & $506 / 1020(50)$ & $141 / 241(59)$ & $0.54(0.37$ to 0.79$)$ & $0.0008 \ddagger$ \\
\hline Who smoked & $75 / 236(32)$ & $251 / 1005(25)$ & $45 / 238(19)$ & $2.00(1.27$ to 3.14$)$ & $0.0013 \ddagger$ \\
\hline With ischaemic heart disease & $57 / 231(25)$ & $175 / 989(18)$ & $29 / 237(12)$ & $2.35(1.39$ to 3.97$)$ & $0.0005 \ddagger$ \\
\hline With peripheral vascular disease & $47 / 224(21)$ & $136 / 941(14)$ & $30 / 225(13)$ & $1.73(1.01$ to 2.95$)$ & $0.043 \ddagger$ \\
\hline
\end{tabular}

^Comparing patients from deprived wards with those from prosperous wards.

tKruskal-Wallis test.

$\ddagger \chi^{2}$ test. 